\title{
O lugar das pessoas nos projetos de desenvolvimento no Sertão da Bahia: histórias e memórias a partir de vozes ignoradas
}

\section{Aurilene Rodrigues Lima ${ }^{1}$}

\section{Resumo}

Este artigo discute o modo como as pessoas que habitam o sertão da Bahia são vistas e tratadas, em face da implantação de projetos governamentais que visam o desenvolvimento da região e do Brasil. Histórias e memórias são analisadas a partir de entrevistas feitas para a dissertação do mestrado em Sociologia. Ao longo da história esse povo viveu e vive sob a condição em que a ausência do dominador exerceu o seu domínio, mas, paradoxalmente, possibilitou uma intensa produção existencial. Neste trabalho, percorreremos esse campo, o do ignorado, através de uma nova escuta de suas vozes, através dessas entrevistas. Ouvir as vozes ignoradas nos remete a outros mundos.

Palavras-chave: memória; vozes ignoradas; atenção; sertão.

\begin{abstract}
This paper discusses how people living in the countryside of the state of Bahia, in Brazil, are seen and treated regarding the aspects of governmental projects geared towards the development of their region and the whole Country. Their stories and memories are analyzed by the means of interviews conducted through this master thesis work on Sociology. Throughout history, this people had lived and still lives under the condition of a non-dominance power and, yet paradoxically, this fact has driven an intense existential production. In this work we discuss the field of the ignored, thus giving them a new through our interviews. By listening to ignored voices we open doors to different worlds and possibilities.
\end{abstract}

Keywords: memory; voices ignored; attention; countryside

\section{RESUMEN}

Este articulo debate el modo como las personas que viven en la zona semiárida del estado de Bahía (Brazil) son percibidas y tratadas por lós proyectos de desarrollo implementados por el gobierno em La región. Sus historias y memorias son analisadas por medio de entrevistas hechas para la tesis de maestria en Sociologia. En la historia de esa zona, la gente vivió y aún vive sob la condición de ignorados, em que la ausência del dominador exerció su domínio, pero paradoxalmente, possibilitó una intensa

\footnotetext{
1 Graduada em Pedagogia pela Universidade do Estado da Bahia (1990) e mestrado em Sociologia pela Universidade Federal de Pernambuco (2004). È professora assistente da Universidade do Estado da Bahia. Tem experiência na área de gestão educacional.
} 
producción existencial. En este trabajo, recurriremos ese campo, lo del ignorado, por medio de una nueva escucha de sus voces, por médio de esas entrevistas. Oir las voces ignoradas se nos remite a otros mundos.

Palavras clave: memória; vocês ignoradas; atención; semiárido

\section{INTRODUÇAO}

A região do Sertão da Bahia foi e continua sendo marcada por processos colonizatórios. Inicialmente com a domesticação e matança da população indígena e com a prática de processos de submissão de negros e de foragidos de diferentes partes do país para o desenvolvimento da pecuária, que entrou em decadência no final do século XVIII. A partir da década de 1970, essa gente tem vivenciado a imposição de grandes projetos de desenvolvimento, a exemplo da construção da Barragem de Sobradinho e da implantação de outros projetos em andamento, ao mesmo tempo em que a ausência do Estado foi estratégica para o modelo de desenvolvimento vigente, sendo a sua presença relativamente nova nessa região.

Em 2004, apresentamos no Programa de Pós- graduação em Sociologia da Universidade Federal de Pernambuco a dissertação, Memórias dos Lameiros do Velho Chico: História da população transplantada para Quixaba, Sento-Sé BA com o objetivo de discutir o modo como a memória coletiva dos deslocados com a construção da barragem de Sobradinho tem influenciado a reorganização da vida desses beiradeiros.

Neste trabalho, alguns dos documentos analisados e das entrevistas realizadas são retomados com um novo propósito que é o de discutir o lugar dessas pessoas nesses projetos de desenvolvimento, percorrendo histórias e memórias por meio de suas vozes ignoradas. Tal expressão vozes ignoradas, é apresentada na tese de doutorado da professora Maria Rita do Amaral Assy (2014) como um modo de ver as pessoas dessa região. Uma gente ignorada, que viveu e vive sob a condição em que a ausência do dominador exerceu o seu domínio sobre o povo colonizado, mas, paradoxalmente, foi nesse processo que outros modos de vida ganharam tempo, possibilitando uma intensa produção existencial. 
Nessa perspectiva, as vozes ignoradas conduzem o ouvinte/leitor pelas cenas do que se passou e ao serem ouvidas/lidas em um processo de atenção com concentração sem foco, o pensamento poderá abrir-se para o acontecimento, para a experiência. $\mathrm{Na}$ percepção de Assy (2015, p.1) essa experiência é a mesma do caçador de veados.

A atenção é a da espreita, em que o caçador atenta, percebe a paisagem e a paisagem que o percebe. Um devir-consciente. Todos os seus sentidos estão abertos aos movimentos delicados de um veado no mato e à sensibilidade desse animal. E nessa espera, o inesperado pode acontecer.

Compreendemos as histórias aqui relatadas como inseparáveis das memórias, uma vez que são constituídas por estas, embora se distingam. Concordamos com Montenegro (2001, p.17-18) de que,

...se são distintos, arriscaríamos afirmar também que são inseparáveis. Afinal, compreendemos a história como uma construção que, ao resgatar o passado (campo também da memória), aponta para formas de explicação do presente e projeta $o$ futuro. Este operar, próprio do fazer histórico na sociedade, encontraria em cada indivíduo um processo interior semelhante (passado, presente e futuro) através da memória.

A concepção de memória é entendida aqui como um fenômeno social, que reconstrói o passado a partir das necessidades do presente, de forma seletiva, imprevista e inesperada e que a forma básica, mas não única, de socialização da memória é a linguagem.

Nessa perspectiva, nos valemos da compreensão de Assy (2015, p.5) sobre o campo do ignorado, quando ela afirma que "é possível uma aproximação do ignorado pela escuta de suas vozes”. Vozes carregadas de uma performance própria, de forças inventivas e contagiantes e que por isso provocam no seu ouvinte outras sensibilidades. Ouvir as vozes ignoradas nos remetem a outros mundos.

\section{DESENHO METODOLÓGICO}

O desenho metodológico deste trabalho se aproxima da pesquisa de natureza etnográfica, uma vez que esta permite o uso de técnicas como a observação, a entrevista e a análise documental como suas técnicas principais de coleta de dados; a atenção ao 
modo como as pessoas trazem suas lembranças sobre as coisas, as suas vidas, os eventos e sobre si próprias; a aproximação do pesquisador às pessoas e às situações locais, para estabelecimento de um contato direto e constante com estas; o uso de uma grande quantidade de dados descritivos; o pesquisador como o principal instrumento da pesquisa.

\section{O POVOAMENTO DA REGIÃO - PRESENÇA INDÍGENA}

A região do Submédio São Francisco foi inicialmente habitada pelos índios Cariris, após terem sido expulsos do litoral pelos índios Tupis, conforme Gonçalves (1997). Eles viviam nos lugares onde era possível pescar, caçar e colher frutos, como as serras, os brejos, as ilhas e as margens do rio São Francisco (Opara ${ }^{2}$ na língua indígena). $\mathrm{Na}$ época da colonização dessa região, eram deixados em cada curral "um casal de escravos, dez novilhas, um touro, um casal de equinos e também animais domésticos". (CALMON apud GONÇALVES, 1997). Esses escravos, índios ou foragidos, tornavamse vaqueiros. "A vaqueiragem despistava a atenção do colonizador e deixava o vaqueiro atuar”. (ASSY, 2015, p.3). Nessa atuação, outro modo de vida se fazia.

Nas vozes dos sertanejos, a presença do índio, ainda hoje, é sentida e pressentida. A escravidão, por outro lado, não faz sentido, pois aconteceu de outro modo.

De escravo eu não tenho conhecimento. Agora de índio eu sou. A minha bisavó foi pega através de dente de cachorro. Era braba no mato. E a avó da minha mãe, foi pega a dente de cachorro, era braba, era índia braba... que essas serras aqui era cheia deles e conforme foi chegando muita gente, eles foram saindo e outros foram amansando e tudo. Na realidade hoje acabou problema de índio aqui na área, só tem nas reserva mesmo, lá pra os outro lugar, mas aqui mesmo não existe. Existe assim, a descendência das pessoas que casaram dessa natureza. $\mathrm{O}$ meu cunhado tem uma filha e que tem filho de índio. Ela mora em São Paulo com o filho. Ela trabalha de enfermeira na FUNAI em São Paulo, e aí ela é mãe solteira e ela tem um filho com um índio, descendência de índios. (Seo Dico, 76).

Seo Dico não tem dúvidas quanto a sua origem: “de índio eu sou”, pois, existiram muitos índios naquela região, algumas "pegadas a dente de cachorro, índia braba". Essa expressão se relaciona com histórias de que o escravo que se tornava vaqueiro tinha o

\footnotetext{
${ }^{2}$ Opara significa tonto, perdido, sem rumo. Era assim que os índios viam o seu rio.
} 
hábito de colocar cães de guarda para correrem atrás das índias, para "amansá-las". Os índios habitavam as serras, era "cheia deles". Outros povos foram chegando, portugueses, escravos fugidos do litoral. Os índios foram mudando. Os novos índios passaram a ser problema nesse novo mundo que estava surgindo. "Hoje acabou problema de índio aqui na área”. Existe hoje um outro índio, o da reserva. Mas, ainda existe a descendência, "as descendência das pessoas que casaram dessa natureza".

Seo Zé Apolinário (96 anos) revela que anda sempre acompanhado por índios, por isso, a consideração, o agito no corpo, a leveza e o sentimento de sempre saber o que vai acontecer, na espera do acontecimento.

Agora eu que me considero. Tenho uma parte da serra. Esse povo que trabalha na serra, os índio brabo, é um povo diferente, esses anda comigo. Eu acredito que seja tendo ajuda que eu me curo né? É a gente estando assim, chega uns tempo assim que o povo chega num lugar que o povo dá trabalho. Tem que cair dentro, só não faço é curar, mas trabalhar, trabalho. Trabalho que o cara tá, quando der fé que não, chegou. Dá aquele agitação no corpo, parece que aquele irmão encosta e agora aí tira uns ponto de trabalho, vai cantar, vai rezar, vai pinotar. Deles que ainda bebe, e também o cara bebe, bebe, bebe, quando sai... Bebo, lá no trabalho eu bebo... Não sinto nadinha, agora sinto o corpo ficar maneiro né? Manera o corpo da gente, a gente fica com o corpo maneiro, e dá aquele estilo assim com a gente, aqueles palpite que dá de fazer uma coisa. Eu me sinto bem por isso porque os índio da mata só cura com raiz de pau, é, só pau. Ė o caso é esse aí, de eu não me prestar a doutor, todo mundo diz: é comprimido, eu não sei o que é isso, eu arrumo comprimido mas não sou muito disso não, só mato.

“Eu que me considero". Há uma certeza nessa afirmação. Seo Zé não apenas se considera, mas faz questão de se considerar parte deles, dos índios das serras. É índio mesmo que não sendo. Os índios trabalham nas serras, esses andam com ele. Existem os índios do trabalho, "que o povo dá trabalho... Quando der fé que não, chegou”. O corpo é tomado, fica leve, sente aquele palpite de fazer algo, já sabe, o problema tem solução: é só pau, é só mato. É outro trabalho. O modo indígena de pensar e de se relacionar com o mundo e com a natureza está presente no corpo de seo Zé e de tantos outros moradores desse lugar.

Segundo Gonçalves (1997), a região do Médio e Submédio São Francisco foi historicamente marcada pela violência, seja através da matança de índios, destruição de quilombos, invasão de terras a opressão de todos os tipos. Segundo ele, durante o processo de colonização do país, essa região ficou isolada, por estar distante da capital 
(Rio de Janeiro) e por não ter buscado alternativas à criação de gado, em crise, com o declínio da pecuária.

Para Assy (2015, p.2), no entanto, o termo que melhor se aplica é o de uma gente ignorada e não isolada, explorada, dizimada, oprimida. Ao ser ignorada, essa gente produziu outros modos de existência, inclusive estabelecendo relações com outras "gentes", de outros lugares, fora das relações de poder preestabelecidas. "A invenção de si e do mundo para quem o mundo se acabou tantas vezes na violência da colonização".

No capítulo seguinte, sentiremos com os entrevistados um modo particular de existência: o de viver nos lameiros.

\section{MEMÓRIAS DOS LAMEIROS - ANTES DA MUDANÇA}

A vida na beira do rio, antes da mudança, ou seja, antes da construção da barragem de Sobradinho, se concentrava em dois tempos: o tempo da vazante, que se caracterizava pelo plantio nos lameiros (ilhas e margens do rio) e o tempo da enchente quando as plantações eram feitas nas roças, após as chuvas.

Meus pais vivia de roça. O rio enchia. Vazava. Aí todo mundo ia plantar. Se a planta era a mandioca, era o feijão, era o milho, era a batata. Tudo tinha na época da seca. Agora quando vinha de outubro pra novembro, tornava encher. Todo mundo ia desmanchar sua mandioquinha, botava sua tapioca, botava sua farinha dentro de casa, ia comer. Aí vinha enchente né? Quando a enchente tornava vazar todo mundo ia plantar. (D. Maria, 73).

Para dona Maria, a vida era a roça. O rio enchia e vazava. O movimento das águas orquestrava a vida. As pessoas e o rio se movimentavam juntos. No tempo da vazante, "todo mundo ia plantar... era a mandioca, era o feijão, era o milho, era a batata". 'Era' quer dizer muito e tudo tinha. Quando o rio enchia era o tempo da desmancha nas casas de farinha. Todo mundo "ia desmanchar sua mandioquinha", na maior alegria. Era festa, era cantoria. Para preparar o seu sustento: "botava sua tapioca, botava sua farinha dentro de casa, ia comer". Todo mundo tinha, o tempo e o que era de seu. Todo tempo, no seu tempo. "Aí vinha enchente né? Quando a enchente tornava vazar todo mundo ia plantar”. Era na correria, era muita gente, era muita planta. 
O movimento das águas tinha um ritmo já conhecido dos beiradeiros: enchente, vazante. Tempo cheio, tempo de guardar; tempo seco, tempo de plantar. Todo mundo, nesse mundo, tudo junto. Tudo dependia de todos, de um jeito ou de outro. Todo tempo, era tempo. A intensidade da vida se fazia, nesse fazer.

Além dos lameiros, das roças de chuva e da pesca, os beiradeiros também trabalhavam na navegação, como remeiros ${ }^{3}$. Esta profissão consistia em:

Homens seminus que cantam a sua cantiga monótona de barqueiros, e vão e voltam, levando as suas varas longas e ferradas, jogando-as firmes, certas, n'água, os peitos apoiados sobre elas, tremendo sobre o impulso dos músculos retesados, enquanto debaixo dos seus pés e impelida por estes a embarcação caminha de encontro à corrente, são logo objeto de nossa curiosidade... (SAMPAIO apud GONÇALVES, 1997, p. 108).

Os remeiros eram então contratados pelos barqueiros ${ }^{4}$ para guiarem as suas embarcações rio acima, rio abaixo, transportando mercadorias, que eram negociadas nas cidades beiradeiras. Segundo Gonçalves (1997), o tratamento dado aos remeiros pelos barqueiros, era o mesmo dado aos escravos, uma vez que não tinham assegurado nenhum direito trabalhista e sofriam maltratos, tanto por parte dos barqueiros, quanto por parte da própria natureza do trabalho.

'Seo' José ainda se lembra como se fosse hoje: A vara no peito, o açoite, a ferida, era a marca dos remeiros.

É, é no peito. Aqui ó. Eu mesmo tenho aqui um. Isso meu aqui ó, a senhora pode pegar aqui, isso aqui, essa junta aqui, agora pegue nessa outra. Isso aqui foi uma vara que aqui é alto pra essa né? Isso aqui foi uma vara, ainda escarrei muito sangue, uma vara eu açoitei. Saí dos fios da vara pra não quebrar e não quis sair dos fio. A vara me açoitou, foi me jogar lá um pedaço, e aí bati aqui nesse osso aqui, repare que aqui é mais alto.

Seo José compara os dois ombros, junta, por junta: Foi aqui. No peito. "A senhora pode pegar aqui, isso aqui, essa junta aqui, agora pegue nessa outra". A memória do acontecido está no corpo. "A vara me açoitou, foi me jogar lá um pedaço". Foi a vara que ele usara para auxiliar no movimento da embarcação. Estava com os peitos apoiados

\footnotetext{
${ }^{3}$ Remeiro é o trabalhador da barca. É quem conduz a embarcação.

${ }^{4} \mathrm{Na}$ linguagem regional, barqueiro é o proprietário da embarcação.
} 
sobre ela, com os músculos retesados, quando a vara entrou em luta corporal com ele. Seo José resistiu, mas, não teve jeito. Ficou a marca. A marca dos remeiros do São Francisco.

No vai e vem das águas do Rio São Francisco, distante das grandes cidades que começavam a surgir, um povo caatingueiro, beiradeiro e alguns remeiros, iam inventando a vida. Uma vida marcada pelo tempo, não o tempo do relógio, mas o tempo da duração: do verde, da fartura, da enchente, da vazante, da colheita, da farinhada, da camaradagem. Eram muitos tempos em um tempo. Até que as coisas começam a mudar, drasticamente.

\section{A BARRAGEM ESTÁ CHEGANDO - QUESTÕES DE TERRA E ÁGUA}

Na década de 1970, a região do Baixo Médio São Francisco, especialmente as cidades de Sento-Sé, Remanso, Casa Nova e Pilão Arcado foram surpreendidas com a notícia de que seriam deslocadas para outros lugares em virtude do represamento das águas do Rio São Francisco e a consequente inundação de suas terras, pela barragem de Sobradinho.

Ao todo foram quatro cidades que tiveram as suas sedes e parte de suas terras inundadas. O município de Sento-Sé foi o mais atingido. Segundo dados do relatório "Antecedentes do Projeto Sobradinho" (p.12), foram atingidas neste município 291 famílias na área urbana e 3. 597 na área rural. Ainda segundo esse relatório, na região do reservatório de Sobradinho, antes da barragem, cerca de 30\% das terras eram cultiváveis. A agricultura predominante era a de subsistência, desenvolvida pelas próprias famílias, praticada de dois tipos fundamentais: a de vazante e a de chuva.

Observa-se, portanto, que houve com o deslocamento uma mudança significativa na organização espacial desse município, provocando mudanças na estrutura do sistema produtivo e como consequência, nas relações sociais entre os seus moradores. Antes mesmo da construção da barragem, a obra monumental já atuava.

\section{A HISTÓRIA DE GERVÁSIO}


Antes da construção da barragem, quando a obra ainda era boato, as terras das cidades a serem atingidas passaram a ser vistas com outros olhos. As pessoas com mais posses e mais influentes buscaram logo os seus "direitos". Buscaram os meios para ter as devidas posses, mesmo não sendo os posseiros. Estes são quem de fato as possuía, pois, cuidavam e viviam dessas terras. Para obter as posses, sem serem posseiros, tornaram-se grileiros ${ }^{5}$.

Aconteceu com Gervásio, um velho (posseiro) que vivia com a sua família, mulher e quatro filhos, em uma serra. A serra do Gervásio, como era conhecida na região. Murilo Carvalho ${ }^{6}$ descreve essa serra da seguinte forma:

...quase tão árida como todo sertão. Cactos, mandacarus, vassourinhas, cardos rasteiros, favelas de folhas lustrosas e espinhentas, um ou outro umbuzeiro misturam-se às milhares de plantinhas sem nome e sem cor que aparelham o chão seco da caatinga e sobem pelas ladeiras pedregosas. Em qualquer lugar essa terra não valeria nada, tão distante da água, tão a prumo. Mas o velho piauiense Gervásio descobriu nela, há mais de cinquenta anos, uma grotinha miúda, pobre olho d'água que resistia até mesmo nos tempos de seca mais bruta (p. 112, 1980).

Contam que nesse lugar Gervásio plantava de um tudo, era mandioca, era abóbora, era feijão, era milho, até cana-de-açúcar e algumas árvores frutíferas, como manga e banana. Fazia desmancha na casa de farinha e criava alguns animais, como cabras e porcos. Consumia e vendia esses produtos. Com isso chegou a possuir alguns bens como uma rural, um jipe. Inventou um mundo. Gervásio viveu esse mundo até que começaram a chegar as intimações do juiz, o Dr. Djalma. Gervásio não atendeu aos chamados, pois já sabia do que se tratava: queriam a serra dele. O juiz insistia, mandou os soldados para resolver a questão. Esses foram cumprir o dever transportados no carro do senhor Eurico, o grileiro, reclamante das terras, juntamente com o seu vaqueiro. Seo Eurico e o vaqueiro, como consta no livro Sangue da Terra, ficaram no carro, há uma légua de distância esperando o desfecho. Houve troca de tiros. Soldado Sebastião, um moço de 23 anos, recém-casado, foi logo baleado e morto. Contam que Gervásio lutava

\footnotetext{
${ }^{5}$ Grileiro é a pessoa que se apossa de uma determinada área, usando como documento de propriedade qualquer título (arcaico) de posse.

${ }^{6}$ Jornalista de São Paulo, que publicou essa história no livro: Sangue da Terra - a luta armada no campo, no ano de 1980 ,
} 
com o Soldado Raimundo Grande, portando um facão e o livro de São Cipriano na capanga e que o soldado Raimundo também labutava com o citado livro. Um não conseguia enxergar o outro, ficaram invisíveis. Durante a luta, em um descuido, soldado Raimundo pequeno, já baleado, segundo relato do mesmo, coloca a arma entre as pernas e acerta o alvo. Gervásio estava morto. Dizem que ao verem o pai sem vida, os filhos debandaram, ficando apenas a mulher cobrindo o corpo, que ficou lá, na terra, coberto de folhas.

As pessoas relatam que não demorou muito, chegou a volante de Juazeiro, a mesma que lutou contra Lampião (?). Eram muitos polícias, fortemente armados. Subiram a serra, atearam fogo no que encontraram, foram de casa em casa. Bateram em parentes e vizinhos de Gervásio. Até uma nora do velho, grávida, foi presa e pariu na cadeia. Muitos abandonaram as suas casas.

Anos depois, Milton, o filho caçula, também foi morto pela polícia, durante uma troca de tiros, no povoado de Piçarrão, próximo a serra. Era um domingo. Estava lá, dizem, para vingar a morte do pai. Era conhecido por suas habilidades com a caça e a vida na caatinga. Dizem que era um excelente atirador. Imagino aquele domingo, no povoado de Piçarrão, o seu encontro com os policiais da seguinte maneira:

Havia mistério naquela mata. Um homem era conhecido por suas habilidades de perceber o outro mesmo antes dele aparecer. Foram muitas tentativas de encontrá-lo, muitas trincheiras armadas, várias emboscadas. Ele sempre sabia o que estava para acontecer: sentia, pressentia, recuava, antevia, enganava, sumia, aparecia. Encontrava o que queria. Acertava o alvo a qualquer distância, mesmo sem vê-lo. Mas, naquele dia algo iria acontecer, estava diferente: um sol escaldante, parado no meio do nada, sons imperceptíveis, cheiros misturados. Até a dona de lá partiu em retirada. Naquele instante o vento parou de soprar, as folhas pararam de balançar, os animais se calaram, as águas se perderam, o céu escureceu. Ouviu-se um estrondo, um assobio: caçaram o caçador.

Recentemente tentei conversar com algumas pessoas sobre o que aconteceu, mas, ninguém sabe ninguém viu. As pessoas que quiseram comentar, apenas de ouvir falar, disseram que o corpo de Gervásio ficou estirado em um "pé de manga" e está lá até hoje e que durante a noite vêm uma luz de cor azul brilhante, iluminando a serra. 
Durante anos, os dois casos, tramitaram na justiça sem um desfecho. $\mathrm{O}$ caso de Gervásio está citado no livro: Bahia - violência e impunidade no campo. Análise de dez anos - registro de 1976 a 1987, organizado pela Associação dos Advogados dos Trabalhadores Rurais da Bahia.

\section{HISTÓRIAS E MEMÓRIAS DO DESLOCAMENTO}

Ninguém acreditava que a mudança fosse ocorrer, todo mundo se revoltou, foi o fim do mundo. Para o Estado, os políticos e as elites de um modo geral, Sobradinho seria a redenção da região.

Não acreditava. Mas sempre, sempre vinha aquela relação que todo mundo ia sair. Eu acreditava porque eu tinha certeza que vinha, que aí uns dois anos atrás, que isso não foi no início não, já vinha de dois ano atrás tão vendo? E com esse negócio agora pra aí, acha que vai sair agora? Nunca. [O Parque Boqueirão da Onça ${ }^{7}$ Pois é, acha que vai sair agora? Daqui uns dois ou três ano, muitos já tem até morrido. E aî começaram a barragem lá, quando terminaram, lá vem água, lá vem água subindo, lá vem água... (D. Maria, 70).

Dona Maria não acreditava porque boatos existem muitos, de todo tipo, desde que o mundo é mundo. Esses eram sobre quem iria sair, quem não iria. Pra que sair, para onde ir? O que iria acontecer com as pessoas, com as criações, com as terras? "Se vinha aquela relação que todo mundo ia sair, eu acreditava". Agora acreditava, porque tinha uma "relação", já tinha nomes, que não tinha chegado lá, mas existia. Estava em outro lugar. Ninguém foi lá dizer: é isso, é aquilo, vai ser assim, é aquilo outro. Não foi logo não, houve muito converseiro, muita opinião, mas nada de certo, certeza. As pessoas não foram consideradas, não foram ouvidas. As decisões eram tomadas pelas autoridades, em outro lugar. Aconteceu. De repente: "lá vem água, lá vem água subindo, lá vem água..." Agora, mais uma vez, surgem novos boatos: irão construir um parque nacional de conservação, o "Boqueirão da Onça". Mas como? Quando? E as pessoas? "Pois é, acha que vai sair agora? Daqui uns dois ou três ano, muitos já tem até morrido”.

\footnotetext{
${ }^{7}$ Proposta do governo Federal através do IBAMA, de construção de um Parque de preservação ambiental na região da caatinga de alguns municípios do norte da Bahia, especialmente de Sento-Sé. Este projeto prevê a relocação dos moradores da região.
} 
‘Seo’ José (54 anos) também não acreditava, mas aconteceu. Houve tantas promessas.

\begin{abstract}
Ah! Eu fiquei com medo quando surgiu a mudança. No momento, até eu não acreditava. Eu dizia: ah! Isso não vai acontecer porque, qual é a água que vai ter pra tirar a gente daqui? E aí muitos dizia: vai acontecer. A gente duvidava né? E aí até que aconteceu. A gente viu que ia acontecer. E aí todo mundo tratou de procurar um lugar. E eu não queria vim praqui porque imaginava assim: ei a gente mora no rio aqui, tudo com tanta fartura e a gente ir pro centro da caatinga. Lá a gente vai viver do que? Mas depois eles chegaram com a sugestão: vai ter isso, vai ter aquilo. Tem o transporte pra tirar vocês. Tudo bem, enquanto transporte a gente se conformava, mas depois que mudaram de lá pra cá, pegaram a gente, botaram aqui, aí depois abriu todo mundo e aí a gente ficou nessa aqui.
\end{abstract}

Havia medo, desconfiança, incredulidade. Seo José e os demais moradores imaginavam: "qual é a água que vai ter pra tirar a gente daqui?" Mas, as pessoas sabiam que poderia acontecer porque não dependia deles, era uma determinação de fora, do governo, dos homens da lei, por isso, trataram logo de pensar alternativas. Porém, sair do rio e ir para o centro da caatinga não fazia muito sentido. Mas, "eles", os técnicos da CHESF, que eram muitos, estavam lá o tempo todo, dizendo: "vai ter isso, vai ter aquilo". Houve promessas de todo tipo, mas, depois "pegaram a gente, botaram aqui, aí depois abriu todo mundo e aí a gente ficou nessa aqui”. Era muita gente de fora. Prometiam muita coisa, mas, depois do fato consumado, não havia mais de quem escutar.

A maioria das pessoas resolveu sair nos últimos momentos, com água na cintura. Houve muita resistência, mas no final, cederam à realidade. Foram transportados de caminhão. Alguns para Quixaba, outros para as Agrovilas, Xique-Xique e São Paulo.

Seo João Elias (75) foi incluído na "solução própria", arranjou-se como pode:

Eu fretei uma canoa. Fretei uma canoa. Parece que, não me lembro mais por quanto eu fretei, que já tá com muitos anos. O camarada foi me botar lá, minhas bagagem tudo. Lá comprei uma casa, já tinha comprado a casa. Chegou a hora que cheguei lá só fui pra dentro da casa. [Sobre o tempo da viagem] Eu saí hoje de tarde, andemo a noite, andemo o dia. Fui chegar no outro dia de manhã, dá uns três dia. As água corria muito. Não era como hoje que as água é fraca. As água é tudo morta. Naquele tempo as água corria muito. Canoa sofria muito pra chegar em Xique-Xique, em qualquer ponto aí pra riba, sofria muito. 
Seo Elias fretou a canoa. Era a "solução própria". Cada um por si. Havia um "camarada" que ajudou. "O camarada foi me botar lá, minhas bagagem tudo". Para recomeçar, era preciso levar tudo que tinha. Todas as coisas cabiam em algumas malas, baús, caixotes e só. A casa já estava esperando. Mas, a viagem, essa foi demorada. "Eu saí hoje de tarde, andemo a noite, andemo o dia. Fui chegar no outro dia de manhã, dá uns três dia". Parecia não chegar a lugar nenhum. Foi uma luta com as águas. "Naquele tempo as água corria muito. Hoje as água é tudo morta”.

A CHESF, através de seus técnicos, enxergava tudo velho, os velhos, as casas, as coisas, aquele mundo. Era preciso mudar, de qualquer jeito, com casa, sem casa, pronta, inacabada. Havia muita desconfiança dos deslocados.

Seo Aristeu (71) conta o que aconteceu com sua mãe,

O técnico da CHESF pergunta: Como é o nome dessa velha? Essa mudança tá marcada pra quinta-feira. Eu digo, vai não. Não vai não, porque a casa não tá pronta e ela não vai não. Ela tem dois filho ainda pra responder por ela. Aliás, três, e ela não vai sozinha não. Uma velha doente desse jeito não vai mudar não. Então cês acompanha ela. Eu digo, eu vou. Se a casa tiver pronta, eu vou. Mas ela só não vai não. Ele disse: a casa tá pronta. Eu digo, eu vou mandar um filho meu olhar a casa, se tiver pronta eu vou. Se não tiver, não vou não. Aí mandei o menino olhar. Disse: pai, a casa tá faltando cobrir um lado. Quando pensa que não, o carro chegou. Eu deixei terminando. Quando chegaram faltava terminar pra cobrir a casa, sem porta, sem nada.

O técnico via a "velha" que tinha que mudar. O filho argumentava que a senhora, sua mãe, estava doente e não podia mudar assim, de qualquer jeito. Até porque, já era de se esperar que a casa não estivesse pronta. "Se a casa tiver pronta, eu vou. Mas ela só não vai não. Ele disse: a casa tá pronta. Eu digo, eu vou mandar um filho meu olhar a casa, se tiver pronta eu vou". Nessa discussão, vai não vai. "Quando pensa que não, o carro chegou". Tiveram que ir, não tinha outro jeito, mesmo o menino avisando: "pai, a casa tá faltando cobrir um lado". Teve gente que encontrou a casa destelhada, teve gente que encontrou sem porta. Fora o desconforto de mudar de uma casa grande, com quatro, cinco quartos, mesmo sendo de taipa, para uma casa de dois quartos. Onde botar os meninos?

Percebemos, portanto, que o modo como se deu o processo de relocação da população atingida pela barragem de Sobradinho, tem a ver com o modo ignorado da 
existência dessa gente. Por outro lado, essa ausência ignorada não impediu que essa população reconstruísse novos modos de existência e se reinventasse frente a novas imposições postas pelo modelo de desenvolvimento vigente.

\section{CONSIDERAÇÕES FINAIS - NOVOS MODOS DE EXISTÊNCIA DE CAATINGUEIROS E BEIRADEIROS, FRENTE A NOVOS PROJETOS DE DESENVOLVIMENTO.}

Os membros da população atingida pela construção da barragem de Sobradinho, sejam caatingueiros ou beiradeiros, estão construindo o seu próprio rumo, buscam e trocam informações, percebem o mundo que o percebe nos diferentes tempos e espaços que os constituem: tempo de plantar, tempo de guardar, que não são mais os mesmos. Mas, é preciso se aventurar.

Eu tenho uma rocinha de chuva. De chuva porque perdi o motor. Eu tenho uma roça de vazante, mas o riacho secou. É na beira do riacho. O riacho secou, então não tem água. Eu tenho outra roça de chuva que se torna na beira do asfalto. Daqui é quatro quilômetro. E aí o dia amanhece. Eu tomo café e já estou indo à roça, fico até meio dia. Fico até de tarde trabalhando por lá e a rotina é essa. A não ser o dia que eu não vá para roça. Fico aqui só caminhando mesmo, de casa em casa, discutindo ideia com os colega. (Seo Dico, 76).

A roça agora é de chuva, se não tiver o motor. Pode ser também de vazante, se tiver água. "O riacho secou, então não tem água". Seo Dico tem alternativa, outra roça de chuva, "que se torna na beira do asfalto". Porque não é mais roça. É povoado. Mas, é preciso inventar a vida. A rotina de seu Dico nas roças, é dele e com ele. Não tem mais todo mundo, não tem mais correria, não tem mais alegria: "Fico aqui só caminhando mesmo, de casa em casa, discutindo ideia com os colega". São outros tempos.

Atualmente novas transformações são impostas a essa região. Está sendo proposta a criação de um parque de preservação nacional, Boqueirão da Onça. Segundo o pesquisador da UNIVASF - Universidade Federal do Vale do São Francisco, prof. 
José Alves Siqueira Filho ${ }^{8}$, a região do Boqueirão da Onça, que envolve os municípios de Umburana, Sento-Sé, Sobradinho, Campo Formoso e Juazeiro, possui as maiores cavernas do hemisfério sul, uma flora repleta de espécies raras e espécies ameaçadas de extinção, a exemplo da Onça pintada. Construir o parque possibilita também uma melhora da qualidade do ar, a regulamentação do regime hídrico das chuvas, além de favorecer o ecoturismo. Inicialmente a proposta era a criação de um parque de um milhão de hectares, mas, essa proposta foi inviabilizada. De acordo com o professor, por causa dos reassentados da barragem de Sobradinho, que já tiveram de deixar as suas casas uma vez e que com essa proposta teriam que abandoná-las de novo.

No entanto, ainda segundo professor Siqueira Filho, não podemos esperar mais, as espécies estão desaparecendo, a região "não possui vocação agrícola" e a densidade demográfica é baixa, "não há presença de pessoas", no entendimento do professor. Essa me parece ser a questão principal nesses projetos, certa invisibilidade dos habitantes desses lugares, pois, toma como parâmetro de densidade demográfica outras regiões do país. A vida na caatinga é marcada por relações de tempo e espaço completamente diferenciadas.

Outra transformação já em andamento nessa região é a instalação da indústria eólica. Ainda segundo o professor, as máquinas para a construção do parque nas serras, destruíram 200 quilômetros de caatinga virgem, alterando significativamente o habitat dos animais. A vida das pessoas também está sendo modificada no sentido da organização espaço/tempo e nas relações de sociabilidade e de convivência com a natureza. Estive recentemente no povoado de São Jose, município de Sento-Sé, para ver o que estava acontecendo, tanto no que se refere à proposta da criação do parque Boqueirão da Onça, quanto a instalação do parque eólico. Percebi que nesse lugar não há somente onças, araras, veados, mas, a principal descoberta da indústria: o vento. Os melhores ventos do Brasil para produção de energia eólica. Muito vento e muito barulho também, vindo do movimento que os aerogeradores fazem.

Nesse sentido, como materializar a experiência de vida desses catingueiros e beiradeiros do sertão da Bahia, através de suas vozes ignoradas, percorrendo o modo

\footnotetext{
${ }^{8}$ Em entrevista ao Jornal À Tarde, no endereço http://atarde.uol.com.br/bahia. Acessado em $27 / 05 / 2015$
} 
Revista ComSertões

como enfrentam as mudanças impostas pelos projetos de desenvolvimento, a exemplo da construção da barragem de Sobradinho, da implantação de parques eólicos e o projeto do parque de conservação nacional, Boqueirão da Onça, considerando esse enfrentamento frente ao modo ignorado de suas existências? Esse é um novo caminho a percorrer.

\section{REFERÊNCIAS BIBLIOGRÁFICAS}

ASSOCIAÇÃO DOS ADVOGADOS DOS TRABALHADORES RURAIS - BA (ORG). Bahia - Violência e impunidade no campo. Análise de dez anos - Registro de 1976 a 1987. Editora ODEAM, Salvador, 1987.

ASSY, Maria Rita do Amaral. A força inventiva da voz ignorada. Tese (Doutorado em Psicologia Clínica). Pontifícia Universidade Católica de São Paulo - PUC - SP, 2014.

ASSY, Maria Rita do Amaral. A criação ignorada da existência. Universidade do Estado da Bahia - Juazeiro, 2015.

CARVALHO, Murilo. Sangue da Terra - A luta armada no campo. São Paulo: Ed. Brasil Debates, 1980.

COMPANHIA HIDRELÉTRICA DO VALE DO SÃO FRANCISCO - CHESF. Aspectos Sócio-Econômicos da Implantação do Reservatório de Sobradinho (Relatório Técnico), Departamento de implantação de Reservatórios, Recife, 1980.

GONÇALVES, Esmeraldo Lopes. Opara - Formação histórica e social do Submédio São Francisco. Juazeiro: [s.e], 1997ª

MONTENEGRO, Antonio Torres. História oral e memória: a cultura popular revisitada. 3.ed. São Paulo: Contexto, 2001.

SIQUEIRA FILHO, José Alves. Entrevista ao Jornal à Tarde. Endereço eletrônico: http://atarde.uol.com.br/bahia. Acessado em 27/05/2015. 